\title{
El juicio de ponderación jurídica al seno de la adminsitracion de justicia en México.
}

\section{The judicial weighting trial to the bank of the adminstration of justice in México.}

Esta obra está bajo una Licencia Creative Commons Atribución 4.0 Internacional. DOI: $\underline{10.32870 / \text { sincronia.axxii.n74.28b18 }}$

\section{Elizabeth Leticia Souza Mosqueda}

Departamento de Derecho Privado/Universidad de Guadalajara

(MÉXICO)

ceding@hotmail.com

\section{Martín Moreno Reynaga}

División de Estudios Jurídicos / Univresidad de Guadalajara

(MÉXICO)

a.j.moreno.r@hotmail.com

\section{Leticia Adela Mosqueda Ochoa}

Departamento de Derecho Social/Universidad de Guadalajara

(MÉXICO)

Lety_mos@hotmail.com

Recibido: $31 / 03 / 2018$

Revisado: $26 / 04 / 2018$

Aprobado: 08/06/2018

\section{RESUMEN}

El ordenamiento jurídico mexicano sufrió un cambio sustancial con motivo de las reformas en materia de derechos humanos, provocando como consecuencia directa una nueva forma de impartición de justicia, lo anterior, a partir de la "rematerialización" del máximo ordenamiento jurídico del país, introduciendo un denso contenido sustantivo a partir de las modificaciones que se realizaron a la constitución, así como el reconocimiento expreso de la validez jurídica de los tratados internacionales en materia de derechos humanos. Estos, fueron expresados como principios normativos, que tienen como intención la salvaguarda de la dignidad humana ante cualquier acto, sea público o privado. Al constitucionalizar los derechos en el ordenamiento mexicano, 
implícitamente, se dio apertura a nuevos métodos para la impartición de justicia, verbigratia: la argumentación jurídica; el control de convencionalidad ex officio; la intepretación conforme, entre otros. Dentro de estos métodos se incluye el juicio de ponderación jurídica, que tiene como finalidad resolver antinomias de principios frente al caso concreto, para impedir la mayor afectación a los derechos humanos, y con ello, el ordenamiento jurídico. En el presente artículo se analizará la actividad jurisdiccional frente al juicio de ponderación jurídica.

Palabras clave: Juicio de ponderación jurídica. Antinomias. Principios constitucionales. Control ex officio.

\begin{abstract}
The Mexican legal system underwent a substantial change due to the human rights reforms, causing as a direct consequence a new way of imparting justice, the foregoing, from the "rematerialization" of the maximum legal order of the country, introducing a dense substantive content from the modifications that were made to the constitution, as well as the express recognition of the legal validity of international treaties on human rights. These were expressed as normative principles, which are intended to safeguard human dignity before any act, whether public or private. By constitutionalizing rights in the Mexican legal system, implicitly, new methods for the administration of justice were opened, for example: legal argumentation; ex officio conventionality control; the agreed interpretation, among others. These methods include the legal weighting trial, which aims to resolve antinomies of principles against the specific case, to prevent the greatest impact on human rights, and with it, the legal system. In the present article the jurisdictional activity will be analyzed in front of the legal weighting trial.
\end{abstract}

Keywords: Trial of legal weighting. Antinomies. Constitutional principles. Ex officio control.

\title{
I. La impartición de justicia mexicana y el efecto de irradiación
}

La actividad jurisdiccional del país se ha venido desarrollando bajo la hipótesis que el poder judicial es un mero aplicador de normas ante un conflicto; "aquella consistente en verificar en concreto la violación a de [...] [las] normas (prácticamente, en resolver controversias que tienen como objeto la violación de normas)" (Guastini, 2013, p. 54). El procedimiento de los juzgadores se dedica a la aplicación de las hipótesis previstas en las disposiciones normativas por medio de la subsunción, desestimando la mayor o menor adecuación de tales disposiciones normativas a un ordenamiento de mayor jerarquía.

A partir de la reforma constitucional se implementa una rematerialización de los derechos: 
La incorporación al texto no solo de normas formales, de competencia o procedimientos destinadas a regular el ejercicio de los poderes y la relación éntrelos mismos, sino también y sobre todo de normas sustantivas que pretenden trazar limites negativos y vínculos positivos a lo que dichos poderes están en condiciones de decidir legítimamente (Prieto, 2013, p. 26).

Los limites que toda actividad estatal debe observar fueron contemplados por el legislador delegado en la reforma que realizada al artículo $1^{\circ}$ de la Constitución de los Estados Unidos Mexicanos, específicamente, al párrafo tercero del artículo en cita, donde, de manera expresa se establece como obligación de todas las autoridades la protección y estricta observancia de los derechos humanos en sus actividades orgánicas.

Consecuencia de lo anterior, al interior del poder judicial, es la introducción de nuevas técnicas para la impartición de justicia. "La reforma constitucional en derechos humanos [...] significó un cambio paradigmático en el sistema jurídico en lo concerniente a su interpretación, aplicación y observancia en relación a la protección de derechos humanos [...]" (Álvarez, Becerra y Benítez, 2015, p. 131).

Estos cambios comprenden la forma de entender el sistema jurídico, el cual, ya no se encuentra integrado exclusivamente por reglas, sino que, ahora, se incorporan los principios, a partir de la modificación constitucional y el reconocimiento de la vinculación de los tratados internacionales en materia de derechos humanos. Los principios integran el contenido denso de la constitución, los cuales, son "normas que ordenan que algo sea realizado en la mayor medida posible, dentro de las posibilidad jurídicas y reales existentes" (Alexy, 2014, p. 67). A partir de la acepción de las disposiciones normativas constitucionales como principios, las potestades que ejerzan los órganos estatales no solo están delimitados por las reglas, sino que también están marcados por la constitución, al imanar de los principios una respuesta para todos los casos. Este efecto es conocido como "Efecto de irradiación": 
[L]as normas de derechos [humanos] contienen no solo derechos subjetivos de defensa del individuo frente al Estado, sino que representan, al mismo tiempo, un orden valorativo objetivo que, en tanto decisión básica de derecho constitucional, es válida para todos los ámbitos del derecho y proporcionan directrices e impulsos para la legislación, la administración y la jurisdicción (Alexy, 2014, p. 465).

Siguiendo el presente efecto que se introduce en nuestro sistema jurídico a partir de la reforma en derechos humanos, surge en México el fenómeno jurídico consistente en el "control de convencionalidad", que no es más que la manifestación del efecto de irradiación en los diversos ordenamientos jurídicos, consistente en la "actividad por la cual los jueces internos de los distintos Estados partes tienen la obligación al fallar los casos de su competencia, de aplicar la Convención Americana, así como las interpretaciones que haga la corte Interamericana sobre esos derechos" (Quinche, 2016, pp. 27-28). Lo anterior, no es más que el control de la parte sustantiva de la constitución y de los derechos contenidos en los diversos tratados por el reconocimiento expreso que la primera hace respecto de los últimos, así como las interpretaciones que de la misma se hagan por los órganos ex professo para su control realicen, conformando el bloque de constitucionalidad.

Esto implica que los jueces nacionales se vean investidos de dos competencias: la competencia por su materia y la competencia constitucional, que, según el tipo de instancia, ejercerán sobre sus actuaciones. Lo anterior, es resultado de que, como lo explica Zagrebelsky (2011), "la ley, en suma, ya no es garantía absoluta ni ultima de estabilidad, sino que ella misma se convierte en instrumento y causa de inestabilidad". Es así como se atienden a principios superiores por los que se sometan las actuaciones judiciales como límite a sus atribuciones.

Sobre esta actividad, Marroquín (2013) nos brinda un ejemplo de la actividad que ahora los jueces tienen que realizar a causa del efecto de irradiación:

En el caso no es posible atender a la solicitud del Ministerio Público para que, por la insolvencia del sujeto activo del delito, se substituya con prisión la reparación del daño. 
En efecto, aunque es verdad que el artículo 35 del Código Penal del Estado, permite tal substitución, la fracción X[sic] de la Constitución Política la prohíbe, al prevenir que en ningún caso podrá prolongarse la prisión o detención por causa de responsabilidad civil o algún otro motivo análogo, como es el caso de la reparación del daño. Por lo tanto, con fundamento en este último precepto se deniega la referida petición [...] (p. 133).

Empero, la actividad a realizar no representa un ejercicio hermenéutico de facilidad para el juzgador, en atención que, dentro del caso concreto, al realizar esta actividad, puede ser que dos o más principios concurran dentro del mismo caso, debido a su propia naturaleza conflictiva.

La coexistencia de valores y principios, sobre la que hoy debe basarse necesariamente una Constitución para no renunciar a sus cometidos de unidad e integración y al mismo tiempo no hacerse incompatible con su base material [...], exige que cada uno de tales valores y principios se asuma con carácter no absoluto, compatible con aquellos otros con los que debe convivir. Solamente asume carácter absoluto el meta valor que se expresa en el doble imperativo del pluralismo de los valores [...] y la lealtad en su enfrentamiento. (Zagrebelsky, 2013, pp. 15-14).

Es importante tener presente que esta naturaleza de los principios, puede ocasionar conflictos ante la posible incertidumbre que ocasionan por estar en constante coalición. No obstante, la implementación de los mismos al sistema jurídico trae consigo la incrustación de las máximas que giran en torno a ellos para su entendimiento, de las cuales, destaca aquella consistente en más “conflictualismo en lugar de coherentismo" (Prieto, 2013, p. 37).

Los conflictos que tienen lugar ante la convergencia de varios principios dentro del caso jurídico, se suscitan por su estructura intrínseca: 
1. Los principios comprenden una "textura abierta" (Hart, 2012, p. 168), que permite a los tribunales su optimización cuando su contenido se adecua en la mayor medida al caso que se les es presentado;

2. La concretización de los principios en un caso jurídico implica la exclusión de la conducta que se debe ser observada, en tanto que un principio lo admite y el otro lo limita.

Ante esto, el juzgador se ve en un dilema, puesto que primar un principio sobre otro, sin la adecuada iusfundamentación para la aplicación y exclusión de los respectivos principios constitucionales, se convierte en un incumplimiento manifiesto de la obligación a promover, respetar, proteger y garantizar los derechos humanos que se han introducido bajo este tipo de disposición normativa.

Es así como se da apertura a un control difuso: “cualquier juez de la Unión (juez común) puede decretar la no aplicación de una ley que contraríe la Constitución federal debido a su supremacía; pero la determinación solo tiene efectos para el caso jurídico" (Salgado, 2015, pp. 4748).

Así mismo, la Suprema Corte de Justicia de la Nación (2013), ante los conflictos que se pueden suscitar entre los principios, ha pronunciado el siguiente criterio, respecto del control difuso:

\footnotetext{
${ }^{1}$ Según H.L.A Hart, una norma de textura abierta comprende "aquellas áreas de conducta donde mucho debe dejarse para que sea desarrollado por los tribunales o los funcionarios que procuran hallar un compromiso, a la luz de las circunstancias, entre los intereses del conflicto, cuyo peso baria de caso a caso". Esto significa que, dentro de la producción normativa por el legislador, existen normas que carecen de una formulación del supuesto de hecho cerrado, haciendo que el sentido de una norma dependa de la interpretación judicial, para así, concretizar la norma; darle un sentido concreto ante un hecho sometido a la jurisdicción. Lo anterior fue llevado al derecho constitucional, haciendo que los principios tengan la calidad de normas de "textura abierta". Esto se debe a que si se llenan de supuestos fácticos los principios constitucionales que tutelan derechos humanos, se permitiría su inobservancia en los supuestos no contemplados por la norma constitucional. Bajo el esquema de normas con "textura abierta", la protección, garantía, respecto y promoción de los derechos humanos se extiende a cualquier acto, impregnando todo el sistema jurídico por contener una respuesta a todo conflicto.
} 


\section{CONTROL DIFUSO DE CONSTITUCIONALIDAD EX OFFICIO. SUS PRESUPUESTOS FORMALES}

Y MATERIALES DE ADMISIBILIDAD Y PROCEDENCIA. Aun cuando el control difuso de constitucionalidad -connotación que incluye el control de convencionalidad- que ejercen los órganos jurisdiccionales en la modalidad ex officio no está limitado a las manifestaciones o actos de las partes, pues se sustenta en el principio iura novit curia, ello no implica que deba ejercerse siempre, pues existen presupuestos formales y materiales de admisibilidad y procedencia que deben tenerse en cuenta. La ley, la jurisprudencia y la práctica muestran que algunos de esos presupuestos, que de no satisfacerse impedirán su ejercicio, de manera enunciativa son: a) que el juzgador tenga competencia legal para resolver el procedimiento o proceso en el que vaya a contrastar una norma; b) si es a petición de parte, que se proporcionen los elementos mínimos, es decir, debe señalarse con toda claridad cuál es el derecho humano o garantía que se estima infringido, la norma general a contrastar y el agravio que le produce, pues de otra forma, sin soslayar su carácter de conocedor del derecho, el juzgador no está obligado a emprender un estudio expreso oficioso de los derechos humanos o preceptos constitucionales o convencionales que se le transcriban, o que de manera genérica se invoquen como pertenecientes al sistema; c) debe existir aplicación expresa o implícita de la norma, aunque en ciertos casos también puede ejercitarse respecto de normas que, bien sea expresa o implícitamente, deban emplearse para resolver alguna cuestión del procedimiento en el que se actúa; d) la existencia de un perjuicio en quien solicita el control difuso, o bien irrogarlo a cualquiera de las partes cuando se realiza oficiosamente; e) inexistencia de cosa juzgada respecto del tema en el juicio, pues si el órgano jurisdiccional ya realizó el control difuso, estimando que la norma es constitucional, no puede realizarlo nuevamente, máxime si un juzgador superior ya se pronunció sobre el tema; f) inexistencia de jurisprudencia obligatoria sobre la constitucionalidad de la norma que emiten los órganos colegiados del Poder Judicial de la Federación, porque de existir, tal criterio debe respetarse, pues el control concentrado rige al control difuso y, g) inexistencia de criterios vinculantes respecto de la convencionalidad de la norma general, ya que conforme a las tesis de la Suprema Corte de Justicia de la Nación, los emitidos por 
la Corte Interamericana de Derechos Humanos son vinculantes para los tribunales del Estado Mexicano.

Por lo que, los conflictos que se susciten ante la concretización de varios principios en un caso jurídico, deben ser resueltos con las nuevas herramientas en la sede donde emerge la contingencia, ante la facultad que la constitución le consigna al órgano jurisdiccional para impedir, dentro de la primera instancia, la conculcación de los derechos humanos contenidos en los principios constitucionales.

\section{El juicio de ponderación jurídica y las antinomias de los principios}

Por la esencia de los principios, en un caso jurídico pueden ser dos o más los que se concreticen, ordenando que se realicen actos contradictorios, los cuales, no pueden dejar de inaplicarse por la naturaleza y jerarquía que tienen respecto del sistema jurídico, surgiendo así una antinomia in concreto. Para no afectar el ordenamiento jurídico ante la decisión de cual prevalece, se instruye el juicio de ponderación jurídica.

Éste es entendido como "la acción y efecto de considerar imparcialmente los aspectos contrapuestos de una cuestión o el equilibrio entre el peso de dos cosas" (Prieto, 2014, p. 189). El peso de las cosas que se debe considerar, es el peso que adquieren los principios dentro de los casos jurídicos.

Lo característico de la ponderación es que con ella no se logra una respuesta definitiva para todo supuesto de conflicto, no se obtiene, por ejemplo, una conclusión que ordena otorgar una preferencia siempre al deber de mantener las promesas sobre el deber de ayudar al prójimo, o a la seguridad pública sobre la libertad personal, o a la libertad de información sobre el derecho de honor, sino que se logra solo una preferencia relativa al caso concreto que no excluye una solución diferente en otro caso de conflicto entre las mismas normas; se trata, por tanto, de establecer lo que se ha llamado una "jerarquía movil" [...] (Prieto, 2011, p. 146). 
Mediante este proceso, se decide cual principio cede ante el otro, mediante una "fundamentación iusfundamentalmente correcta" (Alexy, 2014, p. 53), que consiste en un ejercicio hermenéutico para determinar el valor de los principios y su relación con los hechos donde convergen, justificando el significado imperativo de estos enunciados normativos al caso, colmando así la ausencia del supuesto fáctico característico de esta especie de normas. La fundamentación iusfundamentalmente correcta culmina con un primer enunciado normativo concluyente, el cual actualiza sus consecuencias jurídicas a los hechos jurídicos, cuyos argumentos de justificación son exhaustivos.

Para determinar la permanencia de un principio ante la convergencia de dos o varios en un caso, los principios participaran en una "relación de precedencia condicionada. La determinación de la relación de precedencia condicionada consiste en que, tomando en cuenta el caso, se indican las condiciones en las cuales un principio precede a otro" (Alexy, 2014, p. 73).

El caso deja de ser estudiado a partir de normas aisladas cuya aplicación depende exclusivamente de la exacta adecuación de la disposición normativa frente a la cuestión fáctica, en una subsunción. Tratándose de normas constitucionales que se expresan mediante principios, su aplicación es de igual importancia, existiendo un deber estricto de respeto y observancia. Por eso, con la asignación de valores, se establece cual principio precederá a otro por su mayor trascendencia dentro de los hechos jurídicos sometidos a escrutinio judicial.

En efecto, para instituir esta relación jerarquía, el juez no sopesa el valor de dos principios en abstracto y de una vez por todas, sino que valora el posible impacto de su aplicación al caso concreto, Si el resultado que tendría en el caso concreto la aplicación del principio P1 parece más justo (o menos injusto) que el resultado que tendría la aplicación del principio $\mathrm{P} 2$, entonces, en el caso concreto, se prescindirá del principio P2, mientras que, en el caso concreto, se aplicará el principio P1 (Guastini, 2013, p. 140).

La relación de precedencia condicionada se expresa de la siguiente manera: 


\section{$\left(P_{n} \mathbf{P} P_{n}\right) C$}

Esta fórmula sintetiza el método por el cuál un principio cederá a otro, estableciendo la relación de precedencia condicionada. Para ello, a cada uno se le asignará un valor utilizando la denominada formula del peso. Con este procedimiento se contraponen los principios que colisionan en el caso concreto, otorgando un valor a cada uno, el cual se denomina peso.

Esta fórmula expresa que el peso del principio $P_{i}$ en relación con el principio $P_{j}$, en las circunstancias del caso concreto, resulta del cuociente entre el producto de la afectación del principio $P_{\mathrm{i}}$ en concreto, su peso abstracto y la seguridad de las premisas empíricas relativas a su afectación, por una parte, y el producto de la afectación del principio $P_{j}$ en concreto, su peso abstracto y la seguridad de las premisas empíricas relativas a su afectación, por otra (Bernal, 2008, p. 101).

La fórmula mediante la cual se establecen los pesos de los principios es:

$$
G P i_{j} j C=\frac{I P i C \cdot G P i A \cdot S P i C}{W P j C \cdot G P j A \cdot S P j C}
$$

La cual, ha sido simplificada de la siguiente manera:

$$
G i_{j} j=\frac{I_{i} \times G_{i} \times S_{i}}{I_{j} \times G_{j} \times S_{j}}
$$

[L]as variables referidas a la afectación de los principios y al peso abstracto, se les puede atribuir un valor numérico, de acuerdo con los tres grados de la escala tríadica, de la siguiente manera: leve 2, o sea 1; medio 2, o sea 2; e intenso 2, es decir 4. En cambio, a las variables relativas a la seguridad empírica de las premisas fácticas se les puede atribuir un valor seguro: 2 , o sea, 1 ; plausible 2 , o sea, $1 / 2$; y no evidentemente falso 2 , es decir, $1 / 4$ (Bernal, 2008, pp. 101- 102).

La designación del valor de las variables de la fórmula del peso, son atribuidas por el juzgador a partir de la apreciación que haga de la interacción entre los principios dentro del caso jurídico. Sin embargo, esta designación no es arbitraria, puesto que no queda a la libre voluntad de quien ejerce 
la jurisdicción y presencia la antinomia in concreto. Los juzgadores y los participes tienen la carga de argumentar para demostrar la afectación a un principio constitucional por otro. Por lo tanto, "[I]a ponderación conduce necesariamente a la argumentación constitucional” (Gil, 2009, p. 148).

Mediante la argumentación que se realiza sobre los principios concurrentes de derechos humanos que ocasionan la antinomia in concreto, se justifica su alcance determinado previamente por la interpretación que se hace de estos en relación con los hechos, colmando su "textura abierta" y así, permitir el ejercicio racional jurisdiccional.

[L]a virtualidad de la ponderación reside principalmente en estimular una interpretación donde la relación entre las normas constitucionales no es una relación de independencia o de jerarquía, sino de continuidad y efectos recíprocos, de manera que, hablando por ejemplo de derechos, el perfil o delimitación de los mismos no viene dado en abstracto y de modo definitivo por las fórmulas habituales [..], sino que se decanta en concreto a la luz de la necesidad y justificación de la tutela de otros derechos o principios en pugna (Prieto, 2014, p. 191).

En este ejercicio, los partícipes tendrán que resolver el conflicto suscitado, superando los obstáculos con las técnicas de argumentación jurídica. Esto, puesto que el derecho "es una realidad dinámica y que consiste no tanto -o no tan solo- en una serie de normas [...], cuanto -o también- en una práctica social compleja que incluye, además de normas, procedimientos, valores, acciones, agentes, etc." (Atienza, 2012, p. 124).

En el proceso de la ponderación, los principios se analizarán junto con los elementos externos al derecho, que los dotan dentro de la situación de facto, de un sentido que debe prevalecer por su contenido sustancial. Al respecto, Gil (2009) expone:

En el proceso de ponderación, el primer paso consiste en constatar qué caso o supuesto de hecho queda subsumido por dos principios que colisionan. El segundo paso se traduce en evaluar cual de los principios en pugna tiene mayor "peso" para luego establecer una relación de procedencia condicionada. El último paso se verifica con la construcción de 
una regla iusfundamental, que subsumirá todos aquellos casos en donde se registre una idéntica colisión en el marco de similares condicionamientos fácticos (Pp. 147-148).

Las inferencias lógico-jurídicas que integran las interpretaciones con las que se asignan los valores para cada variable de la fórmula del peso, pueden estar debidamente deducidas de la jurisprudencia que emana del Poder Judicial de la Federación, en aquellos casos donde quede precisado el alcance de los principios mediante criterios que han seguido la denominada corriente de la jurisprudencia de conceptos: "cada proposición jurídica puede ser lógicamente obtenida desde las demás" (Díez-Picazo, 2011, p. 263).

Este tipo de jurisprudencia permite a los partícipes, distinguir los derechos subjetivos tutelados por los principios constitucionales que se encuentra en conflicto, demostrando cual es, en un primer paso, los principios en pugna. Después, según las particularidades del caso, el participe debe apreciar cómo es la afectación del principio dentro del caso: si este es afectado o interviene a otro principio. Identificado lo anterior, y atendiendo a la escala tríadica, deberá precisar si la afectación o intervención se da en una proporción leve, medio o intenso. Para determinar su afectación, es preciso atender que "[c]uanto mayor sea el grado de la falta de satisfacción o de la afectación de un principio, tanto mayor tiene que ser la importancia de la satisfacción del otro" (Alexy, 2014. P. 138).

Para determinar la satisfacción o afectación los principios, se deben analizar bajo un criterio de valoración, que, "[p]or lo general, se valora de acuerdo con varios criterios entre los cuales debe ponderarse, porque tienen un carácter contrapuesto" (Alexy, 2014. P. 123). Los valores utilizados son buenos, no bueno y malo.

Cuando la afectación es mala, corresponde a la variable de a escala tríadica señalada como intensa; si es no bueno, su correspondiente en la escala tirada es medio; cuando es bueno, su correspondiente es leve. Los valores correspondientes a la satisfacción, son contrarios a los utilizados en relación a la afectación del principio. Para determinar el valor de la satisfacción o 
afectación, se considerará a la comparación de la legitimidad de la satisfacción del principio dentro de la esfera jurídica de los partícipes.

Por otro lado, existe la cuestión de la segunda variable de la fórmula del peso: el peso abstracto. Se ha criticado por la discrecionalidad que le otorga al juzgador:

La ponderación supone una fuerte dosis de discrecionalidad, ésta desemboca en el judicialismo, y el judicialismo, que representa la supremacía del poder elitista y no democrático, arruina el imperio de la ley y las prerrogativas del parlamento (Prieto, 2014, p. 206).

Esto, ante el temor de una creciente irracionalidad judicial, considerando que:

[Los] bienes o valores que han de ser ponderados en el caso concreto convierten al Tribunal en un negociador de valores, en una "instancia autoritaria", que invaden las competencias del legislador y que "aumenta el peligro de los juicios irracionales porque con ello cobran primacía los argumentos funcionalistas o costa de los argumentos normativos" (Prieto, 2014, p. 208).

Esta apreciación se funda en la libertad que tiene el juzgador para decidir el valor que se le asignara al peso abstracto dentro de la fórmula del peso.

Empero, el razonamiento con el que el juzgador asigne el valor a esta variable no quedara a su libre voluntad, considerando que el sistema jurídico tiene como fundamento dos "principios más generales del derecho, su última 'base y fundamento'; son los valores de 'justicia' y 'seguridad"' (Ferrer y Sánchez, 2016, pp. 78-79).

La designación que del valor se haga al peso abstracto de los principios en colisión, no atiende al libre razonamiento que el juzgador haga respecto del caso jurídico, sino que es el resultado de un procedimiento lógico-jurídico donde se estiman los principios que colisionan, los hechos que establecen la antinomia in concreto y, la mayor conservación de los dos principios más generales del derecho, a partir de concretización de los principios que convergen en el conflicto. 
Por último, la seguridad empírica de las premisas fácticas, por su propia naturaleza, no pueden quedar constreñidas a un ejercicio argumentativo. Dentro de esta variante de la fórmula del peso, para resolver la antinomia in concreto, las manifestaciones externas deben ser evaluadas en el proceso, resolviéndose sobre "la seguridad de los presupuestos empíricos, que se relacionen con el significado que la respectiva medida tenga en el caso concreto para la no realización del $P_{i}$ y la realización de $P_{j}^{\prime \prime}$ (Alexy, 2003, p. 23).

Lo anterior implica el estudio de los hechos del caso en relación con la antinomia in concreto. "La verdad de los enunciados empíricos se prueba" (Capella, 2006, p. 20). Los partícipes se ven ante la necesidad de probar cuales son los presupuestos empíricos sobre las manifestaciones fácticas que causa la antinomia in concreto, sea en beneficio o en perjuicio ante la satisfacción o afectación de un derecho subjetivo por la concurrencia de dos o más.

La diferencia entre las pruebas de un procedimiento jurisdiccional a las de la fórmula del peso para la ponderación, es la valoración de las mismas. Mientras las que pertenecen al procedimiento per se, se valoran conforme los códigos que rigen la materia, en el juicio de ponderación jurídica, la valoración se establecerá a partir de la siguiente constatación de las premisas empiricas: seguro: $2^{0}$, o sea, 1 ; plausible $2^{-1}$, o sea, $1 / 2$; y no evidentemente falso $2^{-2}$, es decir, $1 / 4$.

El juzgador, con estos elementos, procede a realizar el juicio de ponderación, cuyo resultado, es una regla iusfundamental, con la cual se resolverá el caso.

Cuando, mediante una disposición de derecho fundamental, se ha llevado a cabo alguna determinación relacionada con las exigencias de principios contrapuestos, se estatuye con ella no solo un principio sino también una regla. Si la regla no es aplicable sin llevar a cabo una ponderación previa, entonces, en cuanto regla, es incompleta. [...] Por lo tanto, las determinaciones adoptadas a nivel de reglas preceden a las determinaciones alternativas que, tomando sólo en cuenta los principios, son igualmente posibles (Alexy, 2014, p. 113). 


\section{Los jueces ordinarios frente a las antinomias in concreto de los principios}

Las antinomias in concreto entre dos principios, pueden suscitarse al interior de un procedimiento jurisdiccional, donde, dictadas las providencias correspondientes, puede ser el caso que la deliberación del juzgador implique la concretización de dos o varios principios que vinculan su observancia, con resultados contradictorios.

Ante ello, en atención a la rematerialización de la Constitución Política de los Estados Unidos Mexicanos, los jueces, en el ámbito de su competencia, deben de ejercer un control de constitucionalidad/convencionalidad, acorde al siguiente criterio del SCJN (2012):

\section{CONTROL DE CONSTITUCIONALIDAD Y DE CONVENCIONALIDAD (REFORMA} CONSTITUCIONAL DE 10 DE JUNIO DE 2011). Mediante reforma publicada en el Diario Oficial de la Federación el 10 de junio de 2011, se modificó el artículo 1o. de la Constitución Política de los Estados Unidos Mexicanos, rediseñándose la forma en la que los órganos del sistema jurisdiccional mexicano deberán ejercer el control de constitucionalidad. Con anterioridad a la reforma apuntada, de conformidad con el texto del artículo 103, fracción I, de la Constitución Federal, se entendía que el único órgano facultado para ejercer un control de constitucionalidad lo era el Poder Judicial de la Federación, a través de los medios establecidos en el propio precepto; no obstante, en virtud del reformado texto del artículo 10. constitucional, se da otro tipo de control, ya que se estableció que todas las autoridades del Estado mexicano tienen obligación de respetar, proteger y garantizar los derechos humanos reconocidos en la Constitución y en los tratados internacionales de los que el propio Estado mexicano es parte, lo que también comprende el control de convencionalidad. Por tanto, se concluye que en el sistema jurídico mexicano actual, los jueces nacionales tanto federales como del orden común, están facultados para emitir pronunciamiento en respeto y garantía de los derechos humanos reconocidos por la Constitución Federal y por los tratados internacionales, con la limitante de que los jueces nacionales, en los casos que se sometan a su consideración distintos de las vías directas de control previstas en la Norma Fundamental, no podrán hacer declaratoria de inconstitucionalidad de normas generales, 
pues únicamente los órganos integrantes del Poder Judicial de la Federación, actuando como jueces constitucionales, podrán declarar la inconstitucionalidad de una norma por no ser conforme con la Constitución o los tratados internacionales, mientras que las demás autoridades jurisdiccionales del Estado mexicano sólo podrán inaplicar la norma si consideran que no es conforme a la Constitución Federal o a los tratados internacionales en materia de derechos humanos.

En estricto cumplimiento a este deber constitucional, al presentarse una antinomia entre principios in concreto, los jueces deben realizar un juicio de ponderación jurídica para proveer, sin violentar el máximo ordenamiento del sistema jurídico mexicano, sobre el principio que ha de preceder dentro del caso jurídico, estableciendo una regla de derecho iusfundamental para tal efecto

Este procedimiento se presenta ante el juez natural como un incidente a la litis planteada.

[P]ueden surgir [dentro de los procedimientos] cuestiones de carácter accesorio o incidental, que deben tramitarse paralelamente al proceso principal o como artículos de previo y especial pronunciamiento, que requieren de una solución que puede afectar la marcha del proceso o permiten substanciar, algún artículo con motivo del mismo proceso o de la ejecución de la sentencia. Estos pequeños procesos [...], se les llama Procesos Incidentales (Vizcarra, 2015, p. 187).

Contrario a lo sostenido por la SCJN en la tesis P.LXX/2011 (9a) (2011), este incidente debe de aperturarse por cuerda separada, para dirimir el procedimiento incidental innominado, de carácter constitucional y convencional, por las siguientes razones:

1. Dentro de este procedimiento, deben ofrecerse medios de convicción para probar las manifestaciones fácticas que los presupuestos empíricos implican sobre el caso jurídico;

2. A las partes se les debe de conceder la oportunidad de "participar en los procedimientos [...] y el ejercicio [...] de las facultades de hacer argumentaciones, afirmaciones, aportar pruebas, y las capacidades de rebatir los argumentos de los demás y de autocriticarse" (Bernal, 2008, p. 337). 
3. Debe suspenderse el procedimiento en tanto no se resuelva la antinomia in concreto de los principios que colisionan dentro del caso jurídico. Lo anterior, porque la incertidumbre sobre la precedencia de un principio sobre otro, implica la transgresión a un principio más general: la seguridad, en este caso, jurídica. "[P]ermitir que se dé o se persista su afectación, vulnera la propia convivencia social” (Ferrer y Sánchez, 2016, p. 65).

Esto supone que en el incidente plantado, el juzgador debe resolver de previo y especial pronunciamiento, en un procedimiento sumarísimo que ya no tiene como objetivo reestablecer al afectado en su derecho violentado. En este procedimiento incidental de esencial constitucional/convencional, el juez ponderara dos principios en el interior del caso jurídico que colisionan ante una deliberación que implica su convergencia, para así obtener una regla especifica al caso con la cual resuelva el conflicto, sin afectar de manera autoritaria la Constitución, ante la publicidad de sus decisiones en un procedimiento donde las partes actúen en igualdad de oportunidades.

Aunado a ello, el juzgador está limitado a resolver el juicio de ponderación jurídica, puesto que debe seguir los criterios de interpretación de los derechos humanos que el artículo primero párrafo segundo de la Constitución Política de los Estados Unidos Mexicanos prevé para los ejercicios hermenéuticos donde se decida sobre casos jurídicos en que estén implicados los principios que contienen normas de derechos humanos.

El resultado tiene que seguir los lineamientos de la interpretación pro homine:

PRINCIPIO PRO PERSONA. CRITERIO DE SELECCIÓN DE LA NORMA DE DERECHO FUNDAMENTAL APLICABLE. De conformidad con el texto vigente del artículo 10. constitucional, modificado por el decreto de reforma constitucional publicado en el Diario Oficial de la Federación el 10 de junio de 2011, en materia de derechos fundamentales, el ordenamiento jurídico mexicano tiene dos fuentes primigenias: a) los derechos fundamentales reconocidos en la Constitución Política de los Estados Unidos Mexicanos; 
$y, b)$ todos aquellos derechos humanos establecidos en tratados internacionales de los que el Estado mexicano sea parte. Consecuentemente, las normas provenientes de ambas fuentes, son normas supremas del ordenamiento jurídico mexicano. Esto implica que los valores, principios y derechos que ellas materializan deben permear en todo el orden jurídico, obligando a todas las autoridades a su aplicación y, en aquellos casos en que sea procedente, a su interpretación. Ahora bien, en el supuesto de que un mismo derecho fundamental esté reconocido en las dos fuentes supremas del ordenamiento jurídico, a saber, la Constitución y los tratados internacionales, la elección de la norma que será aplicable -en materia de derechos humanos-, atenderá a criterios que favorezcan al individuo o lo que se ha denominado principio pro persona, de conformidad con lo dispuesto en el segundo párrafo del artículo 10. constitucional. Según dicho criterio interpretativo, en caso de que exista una diferencia entre el alcance o la protección reconocida en las normas de estas distintas fuentes, deberá prevalecer aquella que represente una mayor protección para la persona o que implique una menor restricción. En esta lógica, el catálogo de derechos fundamentales no se encuentra limitado a lo prescrito en el texto constitucional, sino que también incluye a todos aquellos derechos que figuran en los tratados internacionales ratificados por el Estado mexicano. (SCJN, 2012, p. 799).

El resultado, debe ocasionar la menor afectación en una dualidad:

1. Para el sistema jurídico;

2. Para los partícipes.

\section{El control concentrado y el juicio de ponderación.}

El control de constitucionalidad, y con este, el de convencionalidad, se aplica de dos maneras, conforme lo ha venido definiendo la SCJN (2011) a partir de la interpretación de la constitución:

SISTEMA DE CONTROL CONSTITUCIONAL EN EL ORDEN JURÍDICO MEXICANO. Actualmente existen dos grandes vertientes dentro del modelo de control de 
constitucionalidad en el orden jurídico mexicano, que son acordes con el modelo de control de convencionalidad ex officio en materia de derechos humanos a cargo del Poder Judicial. En primer término, el control concentrado en los órganos del Poder Judicial de la Federación con vías directas de control: acciones de inconstitucionalidad, controversias constitucionales y amparo directo e indirecto; en segundo término, el control por parte del resto de los jueces del país en forma incidental durante los procesos ordinarios en los que son competentes, esto es, sin necesidad de abrir un expediente por cuerda separada. Ambas vertientes de control se ejercen de manera independiente y la existencia de este modelo general de control no requiere que todos los casos sean revisables e impugnables en ambas. Es un sistema concentrado en una parte y difuso en otra, lo que permite que sean los criterios e interpretaciones constitucionales, ya sea por declaración de inconstitucionalidad o por inaplicación, de los que conozca la Suprema Corte para que determine cuál es la interpretación constitucional que finalmente debe prevalecer en el orden jurídico nacional. Finalmente, debe señalarse que todas las demás autoridades del país en el ámbito de sus competencias tienen la obligación de aplicar las normas correspondientes haciendo la interpretación más favorable a la persona para lograr su protección más amplia, sin tener la posibilidad de inaplicar o declarar su incompatibilidad.

La solución de los conflictos que se originan por las antinomias entre principios, tiene especial atención dentro del control concentrado de constitucionalidad. En este modelo, se ejerce un estudio directo del caso jurídico que afecta al contenido sustantivo de la constitución, para declarar la invalidez del mismo y hacer que sus efectos cesen al interior del sistema jurídico.

Ahora bien, incluir el juicio de ponderación jurídica dentro de uno de los medios de control de constitucionalidad, resulta una afectación a la finalidad de cada medio. Esto, puesto que la intención con la que se institucionalizó cada uno es diferente, y aunque tiene el mismo objetivo, mantener intangible la constitución, su procedimiento, efectos y naturaleza jurídica son disímiles. Esto nos plantea cómo debe operar el juicio de ponderación jurídica dentro de los medios de control de constitucionalidad concentrado. 
La esencia misma del juicio de ponderación jurídica radica en la solución de antinomias entre principios en un caso jurídico. Al suscitarse, podemos presenciar lo siguiente:

1. Nace una pretensión en cada una de las partes que intervienen en el caso jurídico;

2. Las pretensiones son opuestas: una de las partes tiene la intención de exigir la prevalencia de la situación actual, legitimado para pedir a la autoridad jurisdiccional con competencia constitucional que declare la precedencia del principio que le beneficie, siempre que tenga un mayor peso dentro el caso jurídico;

3. Para hacer prevalecer su pretensión, tiene que argumentar sobre la legitimidad de la precedencia; que el principio por el que presenta su pretensión se adecua a los dos principios generales de justicia y seguridad; por último, ofrecer pruebas sobre las manifestaciones de los principios donde pruebe la seguridad empírica de sus premisas fácticas;

4. La decisión se tomará mediante la sentencia de un juzgado especializado en materia constitucional (en el caso mexicano, a través del Poder Judicial de la Federación).

El juicio de ponderación jurídica no se presenta ya como un trámite incidental. Como se observa, es menester que se incluya como un medio de control de constitucionalidad.

Desde el instante en que hay garantías procesales para los derechos constitucionales, estos ya no son "derechos" meramente morales u objetivos políticos, sino que se hacen derechos jurídicos, derechos propiamente dichos. Tanto más, cuanto más efectivos sean dichos procesos de control de constitucionalidad y de correspondiente defensa de los derechos. Radicalmente formulado: no hay en puridad derecho constitucional mientras se cuente con derecho procesal constitucional (García, 2016, p. 16).

Las partes, ajustándose a un procedimiento instituido como medio de control de constitucionalidad, tienen la certeza de que su pretensión será colmada, así como el sistema jurídico no se verá irrogado por la decisión infundada sobre la prevalencia de un principio sobre otro, al expedirse a los 
juzgados y tribunales federales para resolver las antinomias entre principios, cuando lo anterior implique una afectación directa al contenido sustantivo de un derecho humano.

\section{Conclusiones}

La impartición de justicia en los Estados Unidos Mexicanos, sufrió un cambio paradigmático a raíz de la reforma en derechos humanos. Con la rematerialización de la constitución no solo se incluyó un capítulo denso de derechos humanos al interior del país, por las reformas a la carta magna y la inclusión de los tratados internacionales en materia de derechos humanos, sino que, se dio apertura a nuevos métodos para la impartición de justicia.

Estos métodos atienden a la estructura de los derechos humanos, que son positivizados bajo la forma de principios constitucionales. La característica de estos principios radica en la textura abierta, permitiendo su aplicación bajo la concretización por los tribunales.

Esta concretización es causante de antinomias in concreto, que pone en un dilema al juzgador cuando dos o varios principios cobran relevancia dentro del caso jurídico. La forma para resolverla es mediante el juicio de ponderación jurídica, bajo la fórmula del peso. Al ponderar el peso de los principios que colisionan en un caso jurídico, por conectar a varias respuestas contradictorias con el mismo grado de aplicación dentro del sistema jurídico, se determina que el principio que prevalecerá, será el que manifieste un mayor peso sobre los concurrentes mediante la asignación de un valor debidamente calificado con una fundamentación iusfundamentalmente correcta, causando así una menor afectación al sistema jurídico, ante la inaplicación legitima de principio que sede en este ejercicio jurisdiccional.

Los jueces, para estar en condiciones de cumplir con los deberes que la constitución les impone, deben ejercer un control de constitucionalidad en sus respectivas competencias. Esto, dado el sistema jurídico mexicano, hace que el sistema de control de constitucionalidad sea de dos formas: difuso y concentrado. Dentro de la actividad tendiente al control difuso, los juzgadores, de manera incidental, resolverán esta antinomia que transgrede la constitución. En un control 
concentrado, deberá reconocerse su carácter de medio de control para dar una garantía efectiva sobre los derechos humanos.

Con esto, se hace patente que el órgano jurisdiccional no solo se dedica a la aplicación del derecho a un caso en concreto, sino que se convierte en un defensor de los derechos humanos, al realizar los actos con los que estos derechos se vean afectados en su menor medida, mediante el estudio de su satisfacción por conducto del juicio de ponderación jurídica.

\section{Referencias:}

Alexy, R. (2014), Teoria de los derechos fundamentales. Madrid: Centro de Estudios Políticos y Constitucionales.

Álvarez, F., Becerra J., Benítez J. (2015). El constitucionalismo ante el control de convencionalidad, su debate actual. México: Porrúa.

Atienza, M. (2012), El derecho como argumentación. México: Fontamara.

Bernal, C. (2008), El derecho de los derechos: Escritos sobre la aplicación de los derechos fundamentales. Colombia: Universidad Externado de Colombia.

Carbonell, M. (Coomp.). (2014), Argumentación jurídica: El juicio de ponderación jurídica y el principio de proporcionalidad. México: Porrúa.

Diez-Picazo, L. (2011). Experiencias jurídicas y teoría del derecho. Barcelona: Ariel.

Ferrer, E. y Sánchez, R. (2016). El nuevo juicio de amparo: Guía de la Reforma constitucional y la nueva ley de amparo. México: Porrúa.

García, J. (2016). Prólogo. En Pozo, E. Derecho Procesal Constitucional (pp. 11 - 29). Bogotá: Ediciones Nueva Jurídica.

Gil, A. (2009). Escritos sobre neoconstitucionalismo. Buenos Aires: Ediar.

Guastini, R. (2013). Estudios de teoría constitucional. Trad. Miguel Carbonell. México: Fontamara. Hart, H. (2012). El concepto del derecho. Buenos Aires: Abeledo Perrot. 
Marroquín, J. (2013). Técnica para la elaboración de una sentencia de amparo directo. México: Porrúa.

Pozo, E. (2016). Derecho Procesal Constitucional. Bogota: Ediciones Nueva Jurídica.

Prieto, L. (2011). Apuntes de teoría del derecho. Madrid: Trotta.

Prieto, L. (2013). El constitucionalismo de los derechos: Ensayos de filosofía jurídica. Madrid: Trotta.

Prieto, L. (2014). Justicia constitucional y derechos fundamentales. Madrid: Trotta.

Quinche, M. (2016). El control de convencionalidad. México: Ubijus.

Salgado, E. (2015). Manual de derecho procesal constitucional. México: Porrúa.

Suprema Corte de Justicia de la Unión. Semanario judicial de la federación. Recuperado de: https://sjf.scjn.gob.mx

Vizcarra, J. (2015). Teoría general del proceso. México: Porrúa.

Zagebelsky, G. (2011). El derecho dúctil: Ley, derechos, justicia. Madrid: Trotta. 